\title{
Children and Adolescents' Third-Person Perception Regarding Depictions of Violence in Different TV Genres
}

\author{
John CHAPIN, Dr. \\ Professor of Communications \\ Penn State University, United States of America \\ E-mail: jrc11@psu.edu
}

\begin{abstract}
Research in third-person perception (TPP) is well-established. The current study contributes to the literature by examining differences in the perceptual bias attributable to different television genres: Teen Dramas, Crime Dramas, and Super Hero/Fantasy Shows. A field survey of middle school and high school students $(N=1,255)$ documented thirdperson perception regarding depictions of abuse on television watched by children and adolescents, as well as a unique third-person effect: Intended bystander intervention when witnessing peer bullying in real life.
\end{abstract}

Keywords: Third-person perception; Violence on television; Bystander intervention.

According to the University of Michigan School of Medicine (2020) school-aged children watch television an average of 28 hours per week. Much of this viewing is done alone, as the majority of children and adolescents have a television in their bedroom and have access to Internet-based streaming content on other devices. Dozens of studies document that TV viewing displaces reading, physical activity, and family time and is linked with diminished academic performance, sleep problems, obesity, and risky behaviors (for a review, see University of Michigan, 2020). 
American children see an average of 200,000 violent acts on television by the time they complete high school. TV shows often present violence as funny or as appropriate ways to resolve conflict. A longitudinal study from the University of Michigan (2020) concluded the link between childhood TV viewing and aggressive or violent behavior continues into adulthood. This study uses third-person perception (TPP) as a theoretical framework for examining the TV genres most watched by children and adolescents that depict different forms of interpersonal violence and abuse. The study seeks to document both third-person perception regarding depictions of bullying and the behavioral component (third-person effect).

\section{Third-Person Perception}

Third-person perception (Davison, 1983) is the skewed perception that negative media messages affect others more than oneself. The theory has been welldocumented over the past 40 years in a variety of contexts, including recent studies in advertising (Eisend, 2017; Pan \& Meng, 2018), news media (Bjorkdahl \& Carlsen, 2017; Stefanita, Corbu \& Buturoiu, 2018), and social media (Guo \& Johnson, 2020; Wilkinson \& Berry, 2020).

In some cases, people are able to recognize media impact on themselves. A good example of this is of this is Guo and Johnson's (2020) small-scale study $(\mathrm{N}=368)$ of Midwestern college students' perceptions of hate speech on Facebook. The students in this case exhibited first-person perception, believing they were more impacted by hate speech (racist, sexist, or homophobic) than others. Previous studies found similar results related to nasty comments made online by "Internet Trolls" (Chen \& $\mathrm{Ng}, 2017$ ) and child abuse public service announcements (Paek et al., 2013).

In more traditional media where people passively watch, studies related to crime and violence elicit TPP. Research contexts include news coverage of shootings (Hoffner et al., 2017), news coverage of protests (Lo, Wei \& Lu, 2017), depictions of domestic violence on TV medical dramas (Chapin, 2013), and the impact of violent video games (Schmierbach et al., 2011). With less than 10 published studies over the past decade, more research is needed.

\section{Third-Person Effect: Bystander Intervention}

While most TPP studies focus on the perceptual bias itself, a smaller literature highlights why TPP research is still important. People act on their perceptions. The literature refers to this as third-person effect. The most common third-person effect reported is support for censorship or regulation (Eisend, 2017; Rosenthal, Detenber, \& Rojas, 2018; Wilkinson \& Berry, 2020), but TPP is also linked with sharing product reviews and YouTube influencer videos (Chang, Zhang \& Ha, 2019), purchase intentions (Pan \& Meng, 2018), and willingness to seek treatment (Hoffner et al., 
2017). These intended behaviors, or third-person effects, can also lead to action. For instance, a study of college students found Facebook users exhibited first-person perception, believing they were personally harmed more than others by hate speech. They not only supported censorship by the social media platform, they took the active step of reporting instances of hate speech to Facebook for review and potential removal. Similarly, Wilkinson and Berry (2020) found that YouTube users exhibiting first-person perception were more likely to report influencers posting gay content to YouTube, resulting in demonetization of gay content. TPP has been linked with increased political participation (Lo, Wei \& Lu, 2017) and college students sharing alerts about gunmen on campus (Egnoto et al., 2013).

The current study contributes to the literature by considering another active third-person effect, bystander intervention. The majority of studies about exposure to media violence establish a link between exposure to violence on television and violent or aggressive behavior, as well as less empathy for others (University of Michigan, 2020). One study takes this a step further by arguing that watching portrayals of violence on TV makes bystanders less willing to help others (Bushman \& Anderson, 2009).

\section{Perceived Media Reality}

One last piece of the puzzle is perceived media reality. Chapin (2013) found that nurses who believed depictions of domestic abuse on medical dramas like Grey's Anatomy exhibited less TPP than peers who believed the portrayals were unrealistic. This study did not measure bystander intervention. Previous research found similar results in studies of documentary films (Lin, 2013) and reality TV series (Leone et al., 2006). In "Making sense of bad news," the authors argue that media constructions of public disasters compete to form the dominant reality, which influences the public's sensemaking and decision making (Mills \& O'Connell, 2003). In a qualitative study about consumption of violent media, participants made a distinction for the "truth value" of violent content. i.e. audience members reflect more on stories about concentration camps than stories from a galaxy far away. A second category emphasized was relevance. Thus, for a child or adolescent viewer, a 'realistic" portrayal of school violence would trigger significant self-reflection and could ultimately shape attitudes and behaviors. (Bartsch et al., 2016).

Based on the preceding review of the literature, the following hypotheses are posited:

H1: Children and adolescents believe they are more influenced than peers by depictions of violence on television (TPP).

H2: As perceived medias reality increases, TPP decreases.

H3: As TPP increases, intended bystander intervention decreases.

RQ1: Does TPP vary between different TV genres? 


\section{Method}

\section{Procedures and Participants}

Participants were recruited through school-based violence prevention programming provided by an area women's center. Institutional approval for human subjects was obtained prior to data collection by the University's Institutional Review Board. Research instruments were collected prior to the session to avoid skewing the data.

Participants were in grades seven, eight, and eleven from nine school schools in the Mid-Atlantic United States $(\mathrm{N}=1,255)$. Age ranged from 11 to $19(\mathrm{M}=13.6)$. Gender distribution was evenly distributed (51\% identified as male; $48 \%$ identified as female; $1 \%$ identified as non-binary, trans, or other). Consistent with the demographics of the region, participants' races were mostly Euro-Americans (63\%). African-Americans, Hispanic-Americans, Asian-Americans, International, and mixed race or other each represented less than $10 \%$ of the sample. There were no significant differences in study variables attributable to gender or race. Age was inversely related to TPP.

\section{Materials}

Students were asked to identify a show they frequently watch that depicts some form of interpersonal abuse. These shows were individually recorded, then coded into genres.

A follow-up question asked participants to rate the accuracy of the show's depiction of abuse by circling "Not at all," 'Somewhat accurate," or "Mostly accurate." This was used as a measure of perceived media reality.

Third-person perception was measured using a standard instrument which paired two items measured on Likert-type scales ( $1=$ Not at all; $7=$ Very much): "How much would most people in your grade be affected by watching shows like this?" "How much are you affected by watching shows like this?" For both questions, participants were prompted to think about the show they listed as something they frequently watch that depicts some form of abuse. Ratings on the "influence on others" item was subtracted from the "influence on self" item. A negative mean would indicate third-person perception, the belief that others are more affected than oneself by negative media messages.

Bystander intervention was measured using a single item: "if you see a friend or peer making fun of or threatening someone, how likely is it that you will try to stop them?" Responses were measured on a Likert-type scale (1=Not Likely; 7=Very Likely). 


\section{Results}

SPSS software was used for analysis. T-tests, correlations, and linear regression analysis were used for hypothesis testing. Note that TPP is indicated by a negative mean, so signs were reversed for ease of interpretation.

H1 predicted TPP, that children and adolescents believe they affected less than peers by media depictions of abuse. A paired-sample t-test was used to determine if impact on others $(M=2.6, S D=1.6)$ was rated as greater than impact on self $(M=1.8$, $\mathrm{SD}=1.6), t(1141)=16.2, p<.000$. The hypothesis was supported.

$\mathrm{H} 2$ predicted as perceived media reality increases, TPP decreases. Perceived accuracy ratings ranged from "Not accurate at all" (24\%), to "Somewhat accurate" (47\%), to "Mostly accurate" (29\%) Tables 1 and 2 show a significant inverse relationship. H2 was supported.

Table 1. Zero-Order Correlations among Variables Predicting Third-Person Perception

\begin{tabular}{lccc}
\hline & 2 & 3 & 4 \\
\hline 1. TPP & $-.23^{\star \star}$ & $-.07^{\star}$ & $-.06^{\star}$ \\
2. Perc Media Reality & --- & -.03 & -.02 \\
3. Age & & -- & $15^{\star \star}$ \\
4. Bystandar Intervention & & & -- \\
\hline Note: $* p<.05, * \star p<.01$ & & &
\end{tabular}

Table 2. Summary of Linear Regression Analysis for Variables Predicting First-Person Perception

\begin{tabular}{|c|c|c|c|}
\hline & $\begin{array}{c}\text { FPP } \\
\text { Adj. } r^{2}=.16 \\
\mathrm{~N}=1,047\end{array}$ & & \\
\hline Predictor & B & SE B & $\beta$ \\
\hline Perceived Media Accuracy & .50 & .06 & $.23 * * *$ \\
\hline Age & .07 & .03 & $.07 *$ \\
\hline Bystander Intervention & .06 & .03 & $.06^{*}$ \\
\hline
\end{tabular}

Note: $* p<.05, * \star * p<.001$

H3 predicted a third-person effect, that as TPP increases, intended bystander intervention decreases. Bystander intervention ranged from one (Not likely to intervene) to seven (very likely to intervene). Thirty percent of the participants were at the high end of the scale. Only two percent were at the bottom of the scale $(M=5.4$, $\mathrm{SD}=1.5)$. Tables 1 and 2 show a significant inverse relationship. H3 was supported.

RQ1 asked if TPP varied by TV genres. Recall TPP was measured in reference to a TV show identified by students as something they frequently watch that depicts some form of violence. Three genres emerged as frequently watched: Teen Dramas, Crime Dramas, and Super Hero/Fantasy Series. Table 3 shows a breakdown of the 
Table 3. TV Genres and Shows Depicting Interpersonal Violence Most Watched by Participants

\begin{tabular}{|c|c|c|}
\hline Teen Dramas $(\mathrm{N}=263)$ & $\underline{\text { Super Hero/Fantasy }(\mathrm{N}=133)}$ & Crime Dramas $(\mathrm{N}=117$ \\
\hline 13 Reasons Why (41\%) & Stranger Things $(46 \%)$ & Criminal Minds $(37 \%)$ \\
\hline Riverdale $(18 \%)$ & Walking Dead (13\%) & Law \& Order SVU $\left(21^{\circ}\right.$ \\
\hline The Fosters (10\%) & The Flash (12\%) & Chicago $P D(10 \%)$ \\
\hline \multicolumn{3}{|l|}{ Age Range (Mean) } \\
\hline $11-19(\mathrm{M}=14.2)$ & $12-18(\mathrm{M}=13.4)$ & $12-18(\mathrm{M}=13.8)$ \\
\hline \multicolumn{3}{|c|}{ TPP (Mean, Standard Deviation) } \\
\hline$-1.1(1.6)$ & $-1.0(1.6)$ & $-1.7(1.3)$ \\
\hline \multicolumn{3}{|c|}{ Perceived Media Reality (Mean, Standard Deviation) } \\
\hline $1.3(0.7)$ & $1.0(0.7)$ & $1.5(0.6)$ \\
\hline \multicolumn{3}{|c|}{ Intended Bystander Intervention (Mean, Standard Deviation) } \\
\hline $5.5(1.4)$ & $5.5(1.5)$ & $5.6(1.4)$ \\
\hline
\end{tabular}

most popular shows in each genre and differences attributable to each genre. Additional shows were named that didn't reach enough cases to be included. These included cartoons and children's shows (like Rick and Morty) and reality television (like Keeping Up with the Kardashians). The most realistic depictions of abuse were in crime dramas. The three most frequently listed shows account for $68 \%$ of the sample. Other shows included in this genre include Las Vegas PD, NCIS, and Law and Order. It was disturbing to see how many middle school children said they watch Law and Order SVU (Special Victims Unit), since all the episodes focus on sexual crimes.

The most popular genre was teen dramas, with three titles accounting for $69 \%$ of the shows listed by participants. The most popular show, 13 Reasons Why, should be noted because it runs on a streaming service (Netflix) and it features graphic depictions of sexual assault and suicide, in addition to cyber-bullying, stalking, physical violence, and bullying. The Fosters features similar themes, but with a decidedly less dark tone, because it airs on broadcast television. Other shows in this category listed less frequently include Veronica Mars and several iterations of the Degrassi franchise. Table 3 shows that participants recognized that depictions of abuse on the teen dramas they watched were less realistic than crime dramas watched by peers.

An unexpected number of participants mentioned super hero/fantasy shows. The age group skews slightly younger than the other two genres. The three most popular titles account for $71 \%$ of the shows listed. This category had the most titles listed of the three genres included in the study. Other titles included mostly super hero shows like Gotham, Batman, Supergirl, and Green Arrow. Participants recognized this genre as the least accurate depictions of abuse.

Consistent with the findings reported in Tables 2 and 3, TPP is higher among participants watching TV genres with more accurate depictions of violence. 
While Table 1 shows increases across genres, the only significant difference is between Crime Dramas $(\mathrm{M}=-1.7, \mathrm{SD}=1.3)$ and Hero/Fantasy series $(\mathrm{M}=-1.0, \mathrm{SD}=1.6)$, $t(250)=-4.7, p<.000$.

\section{Discussion and Conclusion}

The study contributes to the literature by documenting TPP regarding depictions of abuse on television watched by children and adolescents. Consistent with the previous findings in advertising and public service announcements, TPP increased when students perceived the shows they watch accurately portray different forms of abuse. The shows listed by students as frequently watched ranged from caped heroes vs villains to graphic depictions of rape and murder. It's alarming to learn that around $20 \%$ of eighth graders regularly watch shows like Law and Order $S V U$. The study uniquely explores differences in TPP according to what types of shows children and adolescents actually watch. It's interesting to note no difference in the perceptual bias between students who watch teen dramas vs crime dramas. One could argue teen dramas like the controversial 13 Reasons Why differ little in the graphic depictions of abuse, but focus more on the interpersonal relationships of the teen victims and perpetrators while crime dramas like Law and Order focus more on criminal investigations and procedures. Future research could explore this further through content analysis of popular shows and TPP studies more narrowly targeted to specific shows and themes.

While many TPP studies focus on the perceptual bias without measuring a thirdperson effect, the current study investigated a unique effect: The likelihood of active bystander intervention when confronted by instances of peer bullying. Cumulatively, the findings suggest a possible roadmap to school-based prevention education curriculum that combines a media literacy approach to depictions of abuse with safe approaches to bystander intervention. Knowing that very young children and adolescents are watching graphic depictions of physical violence, sexual assault calls for early education and intervention to help them process what they are watching and learn what to do if and when they are personally confronted with abuse.

The study was an exploration of risk perception associated with watching graphic depictions of abuse conducted with a convenience sample of school students in the Mid-Atlantic region of the United States. The findings may not be generalizable to other populations within the United States or abroad. Allowing the students to identify specific shows they actually watch provided an opportunity to study TPP more naturally, but limited the analysis to smaller sub-sets of the sample. An experimental design assigning larger samples to a finite selection of genres and shows would yield more reliable results.

Future research could extend the findings into education (media literacy) and counseling. It may be beneficial to watch popular television shows with children 
and adolescents to better understand how they process depictions of violence and to explore the educational and therapeutic benefits of media literacy training.

\section{References}

1. Bartsch, A., Mares, M., Scherr, S., Kloß, A., Keppeler, J., \& Posthumus, L. (2016). More than shoot-em-up and torture porn: Reflective appropriation and meaning-making of violent media content. Journal of Communication, 66(5), 741-765. doi: http://dx.doi.org. ezaccess.libraries.psu.edu/10.1111/jcom.12248

2. Bjorkdahl, K. \& Carlsen, B. (2017). Fear of the fear of the flu: Assumptions about media effects in the 2009 pandemic. Science Communication, 39 (3), 358-381. doi: 10.11 77/1075547017709792

3. Bushman B. \& Anderson, C. (2009) Comfortably numb: Desensitizing effects of violent media on helping others. Psychological Science, 21 (3), 273-277.

4. Chang, N., Zhang, R., \& Ha, L. (2019). Does valence of product review matter?: An international journal. Journal of Research in Interactive Marketing, 13(1), 79-95. doi: http://dx.doi.org.ezaccess.libraries.psu.edu/10.1108/JRIM-04-2018-0049

5. Chapin, J. (2013). As seen on TV! Third-person perception in the ER. Communication Annual, 61 (1), 51-60.

6. Chen, G. \& Ng, Y. (2017). Nasty online comments anger you more than me, but nice ones make me as happy as you. Computers in Human Behavior, 71, 181-188.

7. Davison, W. (1983). The third-person effect in communication. Public Opinion Quarterly, 47, 1-15.

8. Egnoto, M., Svetieva, E., Vishwanath, A. \& Ortega, C. (2013). Diffusion of Emergency Information during a crisis within a university. Fournal of Homeland Security and Emergency Management, 10(1), 1-21.

9. Eisend, M. (2017). The third-person effect in advertising: A meta-analysis. fournal of Advertising, 46 (3), 377-394. doi: 10.1080/00913367.2017.1292481

10. Guo, L. \& Johnson, B. (2020). Third-person effect and hate speech censorship on Facebook. Social Media and Society, April-June, 1-12. doi: 10.1177/2056305120923003j

11. Hoffner, C., Plotkin, R., Buchanan, M., Anderson, J., Kamigaki, S., Hubbs, L., Kowalczyk, L., Silberg, K. \& Pastorek, A. (2001). The third-person effect in perceptions of the influence of television violence. Fournal of Communication, 283-299.

12. Leone, R., Peek, W. \& Bissell, K. (2006). Reality television and third-person perception. Journal of Broadcasting \& Electronic Media, 50(2), 253-269.

13. Lin, S. (2013). Perceived impact of a documentary film: An investigation of the firstperson effect and its implications for environmental issues. Science Communication, 35(6), 708-733.

14. Lo, V., Wei, R. \& Wu, H. (2017). Issue importance, third-person effects of protest news, and participation in Taiwan's Sunflower Movement, fournalism and Mass Communication Quarterly, 94(3), 682-702. doi: 10.1177/1077699016670122 
15. Mills, A. J., \& O'Connell, C. (2003). Making sense of bad news: The media, sensemaking, and organizational crisis. Canadian fournal of Communication, 28(3), 323-339. doi: http:// dx.doi.org.ezaccess.libraries.psu.edu/10.22230/cjc.2003v28n3a1374

16. Paek, H., Hove, M., Jeong, H. \& Dillard, J. (2013). When distant others matter more: Perceived effectiveness for self and other in child abuse PSA context. Media Psychology, 15(2), 148-174.

17. Pan, P. \& Meng, J. (2018). Are they celebrity followers? Examining the third-person perception of celebrity-endorsed advertising. Journal of Promotion Management, 24 (2), 233-250. doi:10.1002/ab.21808

18. Rosenthal, S., Detenber, B. \& Rojas, H. (2018). Efficacy beliefs in third-person effects. Communication Research, 45 (4), 554-576. doi: 10.1177/0093650215570657

19. Schmierbach, M. Boyle, M., Xu, Q. \& McLeod, D. (2011). Exploring third-person differences between gamers and nongamers. fournal of Communication, 61(2), 307-327.

20. Stefanita, O., Corbu, N. \& Buturoiu, R. (2018). Fake news and the third-person effect: They are more influenced than me and you. Journal of Media Research, 11(3), 5-23. doi:10.24193/jmr.32.1

21. University of Michigan School of Medicine (2020). Child development and behavior resources. Retrieved from http://www.med.umich.edu/yourchild/topics/tv

22. Wilkinson, W. \& Berry, S. (2020). Together they are Troy and Chase: Who supports demonetization of gay content on YouTube? Psychology of Popular Media, 9(2), 224-235. doi.org/10.1037/ppm0000228 